\title{
Research on Beijing-Tianjin-Hebei Information Platform of Logistics Industry Association Development Situation and Problems Countermeasures
}

\author{
Ma Yinbo, Liu Shaohua, Zhu Linyao, Wan Xiaofan \\ School of Information, Beijing Wuzi University, Beijing, China \\ Email address: \\ Yinbo1991@qq.com (Ma Yinbo), liushaohua2016@qq.com (Liu Shaohua), 1052992312@qq.com (Zhu Linyao), \\ sunnyday1010@163.com (Wan Xiaofan)
}

To cite this article:

Ma Yinbo, Liu Shaohua, Zhu Linyao, Wan Xiaofan. Research on Beijing-Tianjin-Hebei Information Platform of Logistics Industry Association Development Situation and Problems Countermeasures. International Journal of Business and Economics Research. Vol. 5, No. 3, 2016, pp. 75-79. doi: 10.11648/j.ijber.20160503.17

Received: May 9, 2016; Accepted: May 18, 2016; Published: June 4, 2016

\begin{abstract}
The logistics industry association is the bridge of the government and enterprises strengthen the construction of the logistics industry associations at all levels to promote the development of logistics industry, the Beijing-Tianjin-Hebei region so as to promote the healthy and rapid economic development of the Beijing-Tianjin-Hebei region. This paper first analyzed the association of logistics industry information development of the Beijing-Tianjin-Hebei region, and then summarizes the information platform service benefits, in the final analysis industry association information platform construction existing problems and puts forward corresponding countermeasures.
\end{abstract}

Keywords: Logistics Industry Association, Beijing-Tianjin-Hebei Region, Information Platform

\section{Introduction}

Put forward the party's 18 "with Chinese characteristics a new path of industrialization, information, urbanization and agricultural modernization, to promote information and industrialization depth fusion", to carry out in the development of logistics industry, which is an important aspect to promote logistics information industry association, give full play to the logistics industry association communication logistics enterprises and government relations, improve the logistics companies and the government's functions. [1]

Logistics industry association is the bridge of the government and enterprises, can effectively promote the logistics industry standards, policies and laws and regulations of publishing and implementation work to promote; Is the back of the logistics enterprises, can provide enterprises with services, seeks the benefit for the enterprise. Is the platform of the logistics industry development, can provide the logistics personnel education and training, logistics, technical communication and information services, logistics information statistics, etc. [2] So, strengthening the construction of the logistics industry associations at all levels to promote the development of logistics industry in China, and promote healthy and rapid economic development in China.

\section{Beijing-Tianjin-Hebei Association of Logistics Industry Information Development Situation}

Beijing-Tianjin-Hebei logistics information platform construction industry association in the primary stage, showing a much and miscellaneous, general utility function is not high, not much support for the logistics industry to provide information consulting role; Or to organize economic zone, or in administrative organization, and for the development of the integration of the Beijing-Tianjin-Hebei region, association of Beijing-Tianjin-Hebei logistics industry faces a serious problem is contained industry coverage is too narrow and lack of social legitimacy. And social legitimacy is insufficient, is most of the logistics industry association from the state official system. Its member companies are generally not more than $40 \%$ of the total number of whole industry, mostly confined to the original department system, and the vast 
majority of state-owned enterprises. Narrow coverage, which means that the association can master enterprises and the insufficient information of the industry, is difficult to play to comprehensive coordination function. Hebei province XingTai logistics association, for example, XingTai engaged in logistics transportation, warehousing, distribution, shipping, transport, logistics information, such as enterprise unit composed of voluntary, away from direct participation in government departments.

The Beijing-Tianjin-Hebei region logistics industry association in 92. Due to regional development and geographical location, the external environment, such as logistics related industry association in development is uneven, A site of Beijing-Tianjin-Hebei regional logistics information platform, a total of 73 related industries association, no site a total of 19 Beijing-Tianjin-Hebei logistics related industry association.

First for Beijing, it is in the center of political development, economic and geographical conditions have comparative advantages, the development of logistics industry in China is ahead and logistics industry association has the characteristics of large quantity, scale, wide role. [3] Beijing logistics industry association and more miscellaneous, many provincial logistics association (such as Hong Kong logistics association) have also set up in Beijing, is mainly engaged in the development of the national logistics, one of the better known association with China federation of logistics and purchasing, logistics society of China, etc. Tianjin is Combined with own port advantage, most predominantly port shipping association, such as Tianjin international freight forwarders association. The characteristics of the logistics industry in Hebei province association, presents the localization, some cities in Hebei province have a small logistics association, committed to the development of the local logistics, such as XingTai logistics association,

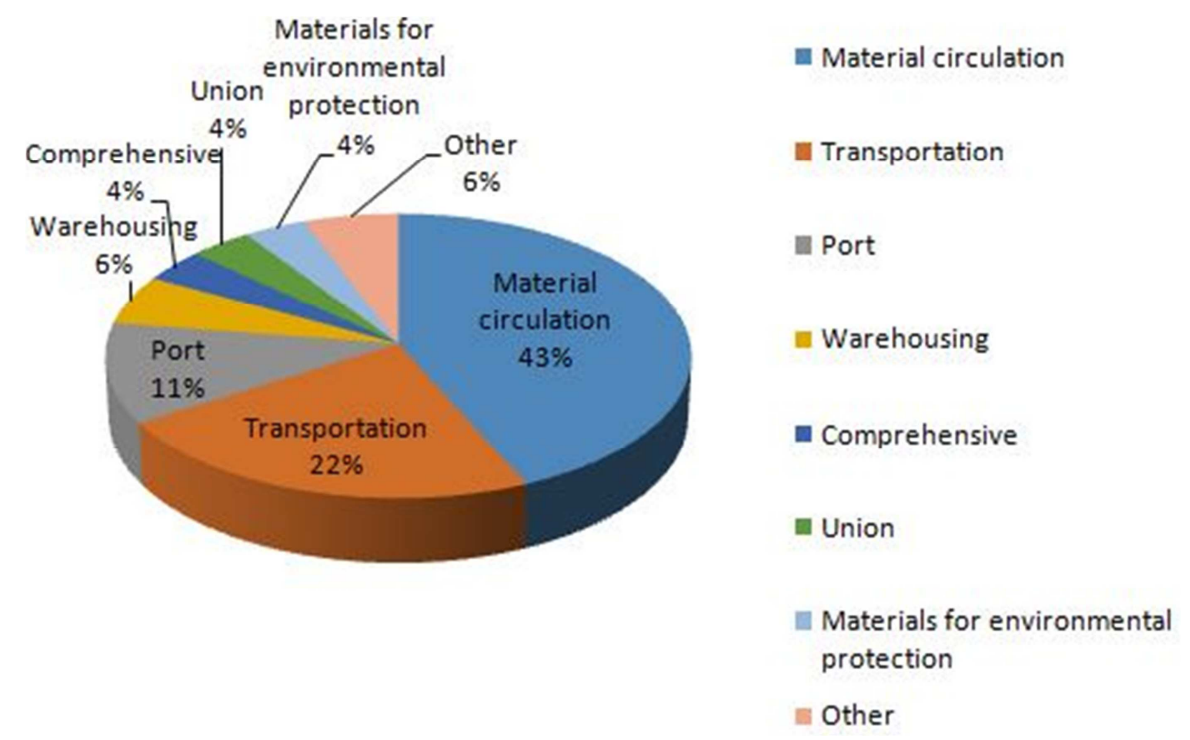

Figure 2. Classification scale map of Beijing logistics industry association.

Tianjin logistics industry association (a total of 13, all have their own information platform, can be divided into
Tangshan logistics association, etc. there are shown in the proportion of the logistics industry association of Beijing-Tianjin-Hebei region (figure 1).

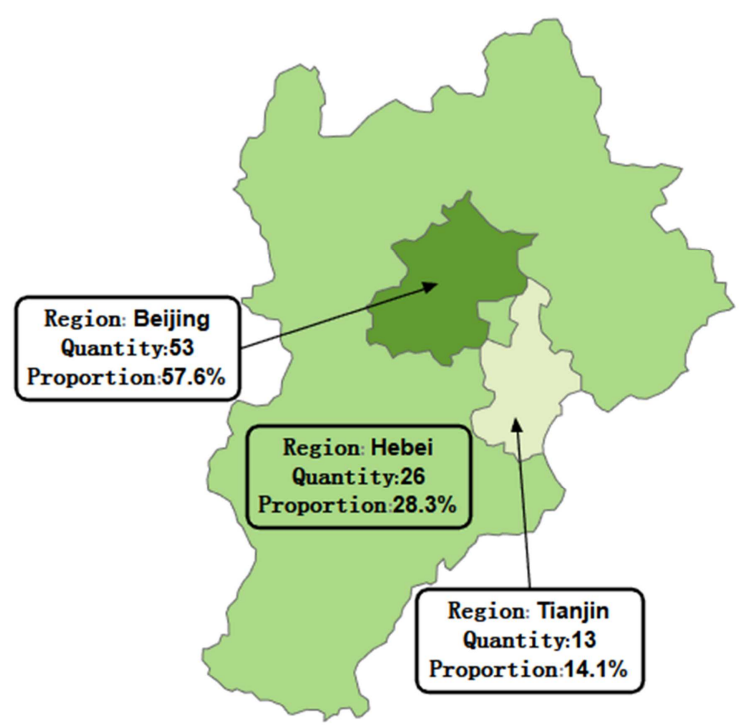

Figure 1. The Beijing-Tianjin-Hebei wing scale map regional logistics related industry association.

From Beijing-Tianjin-Hebei region 92 association of logistics industry information development, a total of 53 in the Beijing area logistics industry association, and information platform built with 52. According to the nature of the logistics industry association and the services provided by the information platform and the function which can be divided into the following eight categories, respectively for comprehensive, ports and port, transportation, supplies, environmental protection, storage and material circulation, its proportion as shown in the figure below (figure 2). comprehensive, transportation, ports, district and county class. There are classification ratios of logistics industry association 
as shown in the figure below (figure 3).

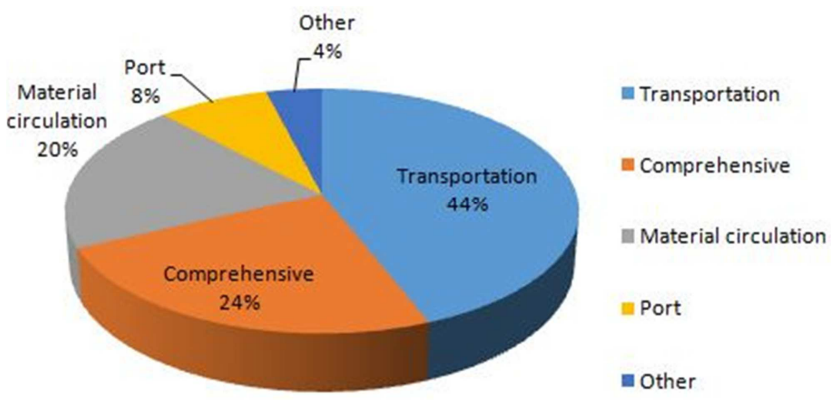

Figure 3. Tianjin logistics industry association classification scale map.

Hebei logistics industry association has a total of 26, including information platform has 14. According to the nature of the logistics industry association and the services provided by the information platform and the function is divided into comprehensive, transportation, municipal areas. It's logistics industry association classification ratio as shown in the figure below (figure 4).

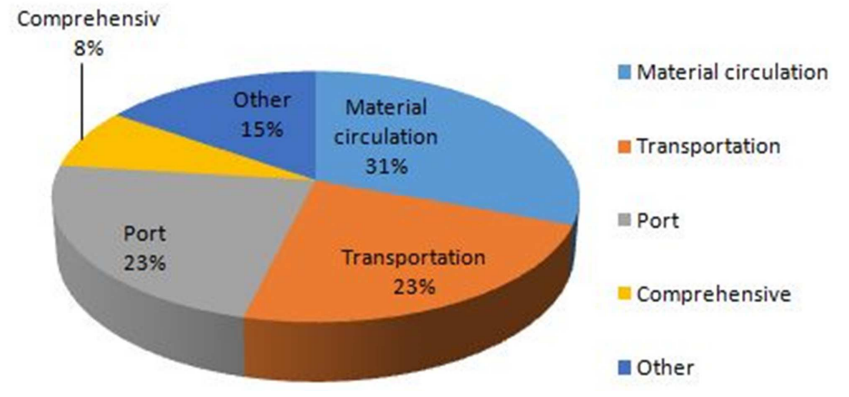

Figure 4. Hebei logistics industry association classification scale map.

\section{Association of Beijing-Tianjin-Hebei Logistics Information Platform Service Benefit}

Beijing-Tianjin-Hebei logistics industry association is the main official website construction on information platform construction, only play the role of good website information exchange platform, can attract more members of an enterprise and logistics professionals to join in, better contribute to the development of China's logistics industry. [4] Beijing-Tianjin-Hebei service benefit information platform of logistics industry association has been highlighted gradually.

From the point of Beijing logistics association, always adhere to the tenet of service, with "small association and great development" development concept, to the government pays special attention to the industry development, the enterprise bigger and stronger to do a lot of work, achieved fruitful results, also made a positive contribution to promote the development of logistics industry in Beijing. By a public information platform to promote industry development, with the support of the Beijing business committee, in 2007, the Beijing logistics association has constructed the "Beijing logistics public information platform". Platform, made some achievements, won the provincial or ministerial scientific and technological progress second prize. At present, the platform has a certain social influence, has made the preliminary social effect. Platform to promote resources sharing, and improve the social logistics resource utilization; Realize the joint distribution, reduce vehicle empty, so as to ease traffic pressure, promote the development of low carbon logistics; Reduce the total logistics cost of society, to promote logistics will play a positive role in promoting industrial upgrading. [5]

Representative of Tianjin modern logistics association, was founded in 2012, its logistics information platform not only includes some countries planning, policy, and introduce some are developing the advanced logistics technology, logistics field, mining and cultivate professional logistics personnel, for the development of Tianjin import and export trade provides a good condition.

Hebei region, such as modern logistics association, Hebei province, and actively national policy. The timely release of information market information, science and technology information, government information and public information, etc., better in the service of logistics enterprises in Hebei province.

\section{Logistics Industry Association Information Platform Construction Problems and Countermeasures}

\subsection{The Existing Problems}

At present, there are all kinds of Beijing-Tianjin-Hebei region logistics industry association, but can really play a role, can the industry development and the development of local economy, only very few can really satisfy the enterprise association, the main problems existing in the following aspects:

\subsubsection{Industry Association Information System, Information Network Construction of the Good and Bad Are Intermingled}

Information system as the basis of information platform construction of industry association, if the construction is bad, it is difficult to play to their role that enterprise and members are hard to come by service effect. From the logistics industry association survey of Beijing-Tianjin-Hebei region, just a website construction platform, there are some industry association not build their own independent website, it is difficult to achieve smooth information exchange, not a very good use of network platform.

\subsubsection{Lack of Required Information Construction Industry Association}

Lack of talents directly restricted the industry association the rapid advance of information construction and application of various kinds of advanced technology and software. Application level is low, although there is a high standard configuration but due to not use or improper use, seriously 
affect the normal office sometimes.

\subsubsection{Industry Association Information Construction for Security System Is not Yet Perfect}

Information construction from planning to the base construction, talent training, software development and application, database management needs to be an effective system to regulate and manage, to ensure the normal operation of the computer and network, ensuring normal development of electronic business. [6] But this security system is still not perfect.

\subsubsection{Industry Association Has Some Detail Problems}

Such as low efficiency, the application level is not high; Small amount of information, information surface is narrow. All these problems need to be improved from the details.

\subsection{The Corresponding Countermeasures}

Association should fully recognize the importance of information construction and information communication. Information is the inevitable requirements of the situation, is to improve the work efficiency, improve service level, the effective ways to achieve resource sharing, has become an important part of the construction of the association. [7] Industry associations should fully recognize the importance of information construction and information communication, enhance the consciousness of the information network, the information construction as to enhance work efficiency and service work, show the image of association of the important means, as an important work in the present and the future, strengthen leadership, clear objectives, planning, implement step by step.

\subsubsection{To Establish and Perfect the Information Network of Association}

First to construction association and members of the enterprise's internal information management system, a special website construction association, provide enterprises with information about the macro environment of enterprise development, market information, technical information, product information, etc., set up information service platform for the enterprise. [8] Second, strengthen communication and exchanges, and in a timely manner from the government, enterprises and various non-governmental organizations on economic development, the advancement of science and technology, and industry association operating experience of the latest information.

\subsubsection{The Introduction of High-Quality Talent Information, Solving the Problem of Lack of Talent}

Information service is the industry association as one of the main content of the enterprise service, therefore, to improve the quality of information service level and it is necessary to introduce and reserves of the corresponding various levels of information talents, such as information acquisition, processing and database processing personnel, information technology and computer systems and network design and development personnel, information analysis research and consulting, information theory and method of research personnel, management information systems and services, etc. Information personnel must have the ability to timely and accurate information about the collection and comprehensive analysis ability, using the modern information technology in information processing, analysis and transfer ability of organization, management and coordination of public relations, social investigation and information product marketing ability.

\subsubsection{Improve the Management Level}

According to operation mode of association, solve the problem of backward management system, security system. Information is a involving multidisciplinary, multiple departments, participation of the whole society, comprehensive and basic work, industry associations should strengthen the comprehensive coordination management, make the terminal, network, database, can produce source, flow, libraries, their respective economies of scale, and can show the whole of the perfect service. [9] To adhere to the principle of the rule of law, perfect system, standardize the management, advance in accordance with the law; To adhere to the principle of efficiency, improve the organization, strengthen the responsibility, efficiency, innovation mechanism. Combined with the government issued new rules, the logistics industry association has some adjustment of the system to make timely, accurate, establish and improve the security system, at the same time, some of the member enterprise feedback should pay enough attention, do not place in a timely manner to improve, make everything work stability and orderly.

\subsubsection{Adhere to the High Efficiency Application, Solve the Problem of Application Level Is not High}

Electronic business is bound to cause work style, the transformation of mode of production and way of life, to improve the work quality and efficiency, realize the business information, office automation, the key is to strengthen the application. [10] First of all, to promote business online office, constantly improve the carrier of portal features. Efforts to improve the administrative efficiency and service quality enhance the industry association management transparency, eventually driving function change. Second, to speed up the resources integration and sharing, sharing, gradual longitudinal resources integration and resource sharing in the system, also with the horizontal sharing of information resources exploitation, so as to improve the overall level of social and public services. Widen the channels of information collection, including: various types of personnel, such as relevant experts, scholars and their peers, government officials, business users, overseas travel, journalists; All kinds of exhibitions, such as trade fairs, exhibitions, exchange fair, etc.; All kinds of meetings, such as industry conference, new product launches; All kinds of institutions, such as government agencies, consultancy, financial institutions, the academic research institutions, such as the Internet. Favorable information resource integration, the construction of large and comprehensive database 


\section{Conclusion}

This article first to the Beijing-Tianjin-Hebei 92 profiles, the information development of the logistics industry association respectively for regional information platform construction is analyzed, summed up the Beijing logistics industry association and more miscellaneous, is mainly engaged in the development of the national logistics; Tianjin combined with their own port advantage, most of the predominantly port shipping association; The characteristics of the logistics industry in Hebei province association, presents the localization, committed to the development of the local logistics, and according to the nature of the logistics industry association and the services provided by the information platform and the function of Beijing-Tianjin-Hebei regional logistics industry association. Then the Beijing-Tianjin-Hebei service benefit information platform of logistics industry association analysis, the result for the service efficiency is gradually apparent. In the final analysis the Beijing-Tianjin-Hebei region the problem: the construction of logistics information platform of industry association industry association information system and information network construction of the good and bad are intermingled, lack of required information construction industry association, association of industry information construction security system is not yet perfect, industry association, low efficiency of the application level of information construction, and puts forward corresponding countermeasures to solve these problems: establishing and perfecting of information network, the introduction of high-quality talent, solve the problem of lack of talent, improve the level of management, adhere to the high efficiency application, solve the problem of application level is not high.

\section{Acknowledgements}

The study is supported by Beijing Key Laboratory of Intelligent Logistics System, (BZ0211), and the project of scientific training program for Beijing Wuzi University college students (2016103050), and Beijing Intelligent Logistics System Collaborative Innovation Center.

\section{References}

[1] Wang Chuanlei, Wang Lan, Feng Shipeng. (2013) Research on Logistics industry association information - in Anhui province for example [J]. Modern intelligence, 33 (4): 67-72

[2] Jiao Wenqi. (2008) Research on regional economic integration of the Beijing-Tianjin-Hebei logistics collaborative [D]. Hebei Normal University.

[3] Guan Tangchun. (2015) Base on the systematic analysis of the regional logistics information platform construction of thinking [J]. Journal of Jilin engineering technical teachers college, 31 (4): 14-17.

[4] Xu Jialiang. (2010) Mutual benefit organizations: China industry association study $[\mathrm{M}]$. Beijing: Beijing Normal University Press.

[5] Huang Shuxian. (2011) Study on the supply condition of service industry association of Guangdong province [J]. Journal of logistics management, (6): 33-34

[6] Chen Ruyu. (2009) Some ideas about strengthen construction of information industry association [J]. Journal of institute, (7): 48-49.

[7] Jiang Yanning, Hao Shuchi. (2011) Association of logistics industry development present situation and the function promotion countermeasures study [J]. Journal of logistics technology, (1): 46 and 47

[8] Wan Lan. (2014) research on Logistic industry association website evaluation system [D]. Anhui University.

[9] Li Yingzheng. (2013) Perfect logistics industry supervision legal system discussed [D]. Jinan University.

[10] Xue Junlin. (2013) Strengthen the industry association function, improving the capacity of Sanming sustainable development of the modern logistics industry $[\mathrm{J}]$. Journal of Shandong industrial technology, (12): 196-197. 